\title{
Persepsi dan Partisipasi Nelayan terhadap Kawasan Konservasi di Pangandaran, Jawa Barat
}

[Perception and Participation of Fishermen to Conservation Area in Pangandaran, West Java]

\author{
Sopiyan Danapraja \\ Sekolah Tinggi Perikanan, Jurusan Penyuluhan Perikanan \\ Jalan Cikaret Nomor 1 Bogor 16001, Jawa Barat \\ Diterima: 13 Juli 2016; Disetujui: 16 November 2016
}

\begin{abstract}
Abstrak
Peningkatan kesadaran dan keterlibatan masyarakat dalam pengelolaan Kawasan Konservasi Laut Kabupaten Kabupaten Ciamis ditujukan untuk meyakinkan masyarakat akan manfaat perlindungan kawasan tersebut. Karenanya peran serta masyarakat harus dilibatkan pada perencanaan, pelaksanaan, pemecahan kendala dan berbagai kemungkinan manfaat yang dapat diperoleh dari pengelolaan kawasan konservasi. Tujuan penelitian mengkaji hubungan karakteristik dengan persepsi dan partisipasi masyarakat, persepsi dan partisipasi dalam pengelolaan Kawasan Konservasi Laut (KKL) Kabupaten Ciamis. Metode penelitian adalah survei melalui analisis korelasi dan multivariat. Responden $72 \%$ di antaranya memiliki persepsi baik (setuju) terhadap pengelolaan KKLD. Persepsi yang baik ditunjukan terhadap program $(64,9 \%)$, pelaksanaan $(55,8 \%)$, pemecahan kendala $(55,7 \%)$ dan manfaat $(62 \%)$.
\end{abstract}

Kata kunci: nelayan, pengelolaan kawasan konservasi, persepsi

\begin{abstract}
Increasing community awareness and involvement in the management of Marine Protected Areas of Kabupaten Ciamis is aimed at convincing the community of the protection benefits of the area. Therefore community participation should be involved in planning, implementation, resolving constraints and possible benefits that can be obtained from conservation area management. The objectives of this research are to examine the relationship of characteristics with perception and community participation, perception and participation in the management of Marine Protected Areas (KKL) of Ciamis Regency. Research method is survey through correlation and multivariate analysis. Respondents $72 \%$ of them have a good perception (agree) on the management of MPAs. Good perception was shown on the program (64.9\%), implementation (55.8\%), constraints $(55.7 \%)$ and benefit (62\%).
\end{abstract}

Keywords: conservation area management, fisherman, perception,

\section{PENDAHULUAN}

\section{Geografis Kabupaten Ciamis}

berada pada $7^{\circ} 40^{\prime} 20^{\prime \prime} \quad-7^{\circ} 41^{\prime} 20^{\prime \prime}$

Lintang Selatan dan 108²0’00” -

10840’00" Bujur Timur. Luas wilayah

Kabupaten Ciamis secara keseluruhan mencapai 244.479 ha. Wilayah selatan Kabupaten Ciamis berbatasan langsung dengan garis pantai Samudera Hindia yang terlihat membentang pada enam kecamatan, yaitu pada areal Kecamatan Kalipucang, juga areal Kecamatan Pangandaran, area Kecamatan Sidamulih

$\triangle$ Penulis korespondensi

Alamat surel: sopiyan@gmail.com 


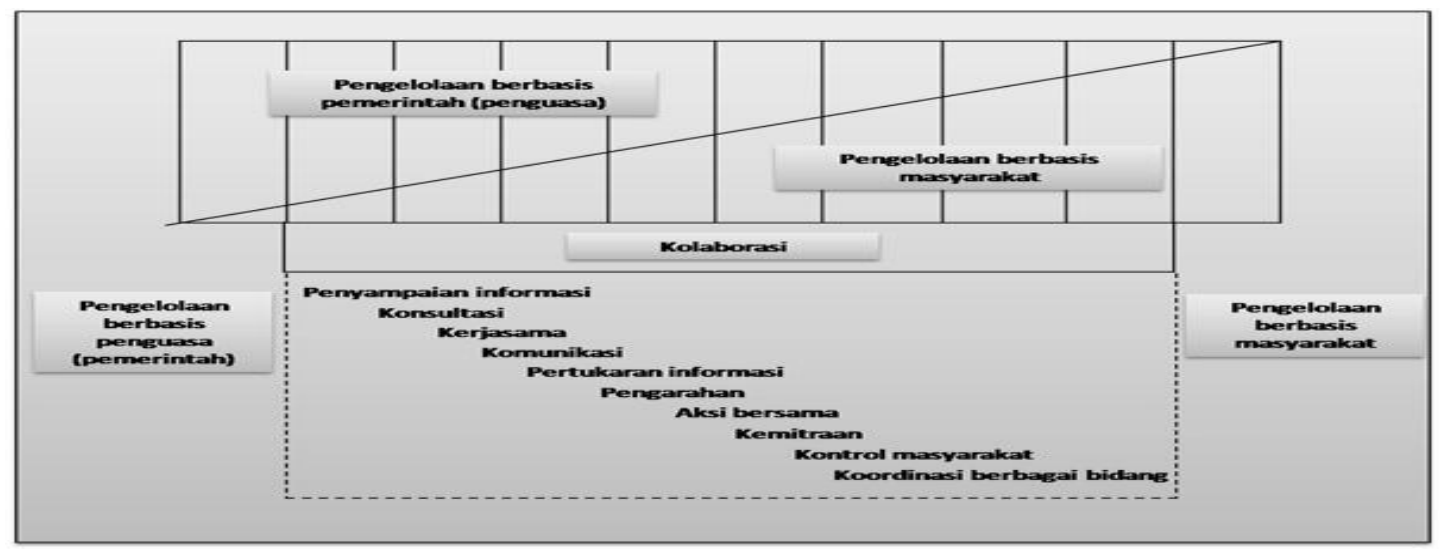

Gambar 1. Konsep co-management dalam pengelolaan wilayah pesisir terpadu sebagai kombinasi manajemen berbasis masyarakat dan manajemen berbasis pemerintah (Pomeroy dan Berkes, 1997).

Parigi, Cijulang dan Cimerak. Dengan panjang garis pantai Kabupaten Ciamis mencapai $91 \mathrm{~km}$, maka Kabupaten Ciamis memiliki wilayah laut seluas 67.340 ha. Pemerintah Kabupaten Ciamis telah menerbitkan Peraturan Bupati Ciamis Nomor 15 tentang Penataan Lokasi Kawasan Konservasi Laut (KKL) Kabupaten Ciamis, sebagai langkah nyata keseriusan Tahun 2008 tentang Pencadangan Lokasi (komitmen) mengelola sumberdaya kelautan dan perikanan. Penerbitan peraturan tersebut merupakan implementasi dari UndangUndang Nomor 27 Tahun 2007 dan Undang-Undang Nomor 32 Tahun 2004.

Salah satu dari faktor kunci untuk membangun pengelolaan area kawasan konservasi adalah juga mengikutkan keterlibatan atau partisipasi masyarakat. Menurut Margono (1985) dalam
Susiatik (1998), bahwa partisipasi masyarakat dalam pembangunan sangat mutlak diperlukan untuk keberhasilan pembangunan, yang pada umumnya dapat dikatakan bahwa tanpa partisipasi masyarakat setiap proyek pembangunan harus dinilai tidak berhasil. Bahkan secara tegas Gawel (1984) dalam White dkk. (1994) menyatakan bahwa tidak ada pengelolaan sumberdaya alam yang berhasil tanpa melibatkan masyarakat lokal sebagai pengguna dari sumber daya alam. Diniah dkk (2012) menambahkan bahwa kepuasan nelayan atas pelayanan institusi pemerintah daerah merupakan salah satu faktor pendorong nelayan untuk ikut berpartisipasi pada programprogram pemerintah.

Tujuan dari penelitian ini adalah mengetahui perspektif atau tanggapan masyarakat nelayan terhadap adanya 
kawasan konservasi. Secara khusus penelitian ini bertujuan untuk mengkaji:

1. Tingkat persepsi masyarakat nelayan mengenai program, pelaksanaan, pemecahan kendala dan manfaat yang ditimbulkan dengan adanya Kawasan Konservasi Laut Kabupaten Ciamis.

2. Peran pemerintah dalam memberikan ruang atau peluang bagi masyarakat nelayan untuk mengelola Kawasan Konservasi Laut Kabupaten Ciamis.

\section{BAHAN DAN METODE}

Penelitian dilakukan pada bulan 3 Mei sampai 14 Juli 2012 di Kawasan Konservasi Laut Kabupaten Ciamis Provinsi Jawa Barat.

Metode pada penelitian persepsi masyarakat terhadap suatu pengelolaan kawasan konservasi ini adalah metode survai. Metode ini juga dilakukan untuk mengumpulkan data tentang fakta dan gejala yang ada serta mencari keterangan secara faktual yang terjadi di lokasi penelitian. Pengumpulan data difokuskan pada kelompok-kelompok masyarakat yang berkaitan erat dengan konservasi laut, yaitu kalangan nelayan dan tokoh masyarakat yang berdomisili di lokasi penelitian.

Jenis data yang akan dikumpulkan dari para responden adalah persepsi masyarakat terhadap keterkaitan mereka dengan KKL Kabupaten Ciamis dan pendapat mereka terhadap tujuan atau manfaat pendirian KKL dan proses pengelolaan KKL. Tujuan dan manfaat pendirian KKL dan proses pengelolaan KKL ini, mencakup perencanaan, serta pelaksanaan kendala serta manfaat yang ditimbukan dalam pengelolaan KKL di suatu kawasan.

Tabel 1. Jumlah responden/ sampel dan alat tangkap

\begin{tabular}{llcc}
\hline No & $\begin{array}{c}\text { Jenis Alat } \\
\text { Tangkap }\end{array}$ & RTP & $\begin{array}{c}\text { Jumlah sampel/ } \\
\text { Reponden (orang) }\end{array}$ \\
\hline 1 & Dogol & 228 & 20 \\
2 & Gillnet & 638 & 25 \\
3 & Tramel net & 303 & 20 \\
4 & Bagan & 29 & 5 \\
5 & Rawai & 469 & 25 \\
6 & Arad & 27 & 5 \\
\hline & Jumlah & 1.658 & 100 \\
\hline
\end{tabular}


Termasuk juga peranan pemerintah daerah dalam memberikan kesempatan atau peluang bagi masyarakat di Kawasan Konservasi Laut untuk juga berpartisipasi dalam pengelolaan Kawasan Konservasi Laut. Hal serupa disampaikan juga oleh Sudiono (2008).

Populasi dalam penelitian adalah Rumah Tangga Perikanan (RTP) nelayan yang melakukan operasi penangkapan di KKL Kabupaten Ciamis. Rumah Tangga Perikanan/RTP yang melakukan operasi penangkapan di Kawasan.

Konservasi Laut pada Daerah Kabupaten Ciamis berjumlah 1.658 orang (BPS Ciamis, 2011), yang menyebar pada enam alat tangkap yang digunakan yaitu dogol, jaring insang (gillnet), jaring tiga lapis (tramell net), bagan, arad dan rawai.

Sampel (responden) ditentukan dengan teknik purposive sampling, dimana pengambilan sampel dihentikan bila jumlahnya telah memenuhi dan sampel yang diperoleh diasumsikan random.

Pengambilan sampel menggunakan teknik sampling kebetulan (accidental sampling) adalah mengambil responden sebagai sampel berdasarkan kebetulan, yaitu siapa saja yang secara kebetulan bertemu dengan peneliti dapat digunakan sebagai sampel bila orang yang kebetulan ditemui cocok sebagai sumber data. Teknik ini biasanya dilakukan karena keterbatasan waktu, tenaga, dan dana sehingga tidak dapat mengambil sampel yang besar dan jauh (Sugiyono 2006).

Keuntungan dari pada teknik ini adalah terletak pada ketepatan peneliti memilih sumber data sesuai dengan variabel yang diteliti (Arikunto, 2002). Perhitungan besarnya responden (sampel) dengan menggunakan rumus Solvin (Umar, 2004), dengan tingkat kesalahan 10\%. Berdasarkan jumlah populasi dan rumus Slovin serta pertimbangan lain, maka jumlah sampel penelitian ini sebanyak 100 responden (Tabel 1).

\section{Metode Analisa Data}

Analisa data penelitian guna menjawab masalah yang telah diajukan (dirumuskan), digunakan teknik analisis sebagai berikut: Data persepi responden dan peran pemerintah masing-masing dianalisis secara univariat (jumlah, mean/rata-rata, dan persentase).

Jumlah nelayan berdasarkan alat $\underline{\text { tangkap nelayan }}=\frac{f_{s}}{N_{h}} \times N$

dimana :

$f_{s}=$ Frekuensi sampel atau responden berdasarkan alat tangkap

$N_{h}=$ Jumlah nelayan berdasarkana alat tangkap 
$N=$ Jumlah nelayan/populasi

$\underline{\text { Rata-rata nelayan berdasarkan alat }}$ $\underline{\text { tangkap }}=\frac{\sum X^{\prime} \times f}{\sum f}$

dimana:

$X^{\prime}=$ Nilai tengah/bobot

$f=$ Frekuensi

$\underline{\text { Rata-rata semua nelayan }}=\sum\left(N_{h} / N\right) \times \overline{X_{h}}$

dimana:

$N_{h}=$ Jumlah nelayan berdasarkan alat tangkap

$N=$ Jumlah nelayan/populasi

$\overline{X_{h}}=$ Rata-rata nelayan berdasarkan alat tangkap

\section{HASIL DAN PEMBAHASAN}

Persepsi Nelayan Responden

Dari sejumlah 100 responden yang diwawancarai dapat diketahui bahwa $72 \%$ mempunyai persepsi yang baik (setuju) dan 20\% sangat baik (sangat setuju) terhadap pengelolaan KKLD Kabupaten Ciamis (Gambar 5). Tingkat persepsi responden meliputi beberapa indikator, yaitu:

Tabel 2. Persepsi responden terhadap program, pelaksanaan, pemecahan kendala dan manfaat KKLD.

\begin{tabular}{|c|c|c|c|c|c|c|c|}
\hline \multirow{2}{*}{ Persepdi } & \multirow{2}{*}{ Mo Percanyan } & \multicolumn{5}{|c|}{ Jamiban Responden } & \multirow{2}{*}{ Jamlab } \\
\hline & & SIS & TS & $\mathbf{K S}$ & 5 & 55 & \\
\hline \multirow{7}{*}{ Program } & 1 & 2 & 9 & 29 & 55 & 9 & 100 \\
\hline & 2 & 1 & 11 & 39 & 43 & 6 & 100 \\
\hline & 3 & 5 & 2 & 14 & 69 & 10 & 100 \\
\hline & 4 & - & 4 & 13 & 73 & 10 & 100 \\
\hline & 5 & $\overline{1}$ & 2 & 6 & 75 & 16 & 100 \\
\hline & 5 & $\overline{1}$ & 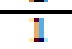 & 5 & 65 & 28 & 100 \\
\hline & 7 & I & 2 & 13 & 74 & 10 & 100 \\
\hline \multicolumn{2}{|c|}{ Jarlah } & 11 & 27 & 119 & 454 & 89 & 700 \\
\hline \multicolumn{2}{|c|}{ Persentase (96) } & 16 & $3 \mathrm{~B}$ & 17 & 64,9 & 12,7 & 100 \\
\hline \multirow{4}{*}{ Felulesanase } & 5 & - & 3 & 19 & 66 & 10 & 100 \\
\hline & 9 & 4 & 4 & 23 & 37 & 12 & 100 \\
\hline & 10 & 5 & 8 & 12 & 91 & 24 & 100 \\
\hline & 11 & 1 & 11 & 5 & 49 & 31 & 100 \\
\hline \multicolumn{2}{|c|}{ Inmlah } & 10 & 28 & 52 & 223 & 77 & 400 \\
\hline \multicolumn{2}{|c|}{ Persectuce (9/6) } & 25 & 7 & 15,5 & 55,8 & 19,2 & 100 \\
\hline \multirow{3}{*}{$\begin{array}{c}\text { Pemecalan } \\
\text { leeadala }\end{array}$} & 12 & - & 8 & 31 & 57 & 4 & 100 \\
\hline & 13 & - & 3 & 35 & 56 & 6 & 100 \\
\hline & 14 & 1 & 4 & 21 & 94 & 20 & 100 \\
\hline \multicolumn{2}{|c|}{ Jamlah } & 1 & 15 & 37 & 167 & 30 & 300 \\
\hline \multicolumn{2}{|c|}{ Persentwe (96) } & 0,3 & 5 & 29 & 55,7 & 10 & 100 \\
\hline \multirow{8}{*}{ Manfaxt } & 15 & - & - & 3 & 32 & -3 & 100 \\
\hline & 15 & - & 2 & $\mathrm{~S}$ & 33 & 37 & 100 \\
\hline & 17 & - & 3 & 7 & 56 & 24 & 100 \\
\hline & 18 & - & 1 & $\mathrm{~S}$ & 72 & 19 & 100 \\
\hline & 19 & - & 1 & 9 & 64 & 26 & 100 \\
\hline & 20 & - & 1 & 12 & 66 & 21 & 100 \\
\hline & 21 & - & - & 4 & 75 & 21 & 100 \\
\hline & 22 & - & 4 & $\mathrm{~s}$ & $4 \mathrm{~B}$ & 40 & 100 \\
\hline \multicolumn{2}{|c|}{ Jamlah } & 0 & 12 & 51 & 496 & 231 & 500 \\
\hline \multicolumn{2}{|c|}{ Persentue $(9 / 6)$} & 9 & 15 & 7,6 & 52 & 28,9 & 100 \\
\hline
\end{tabular}




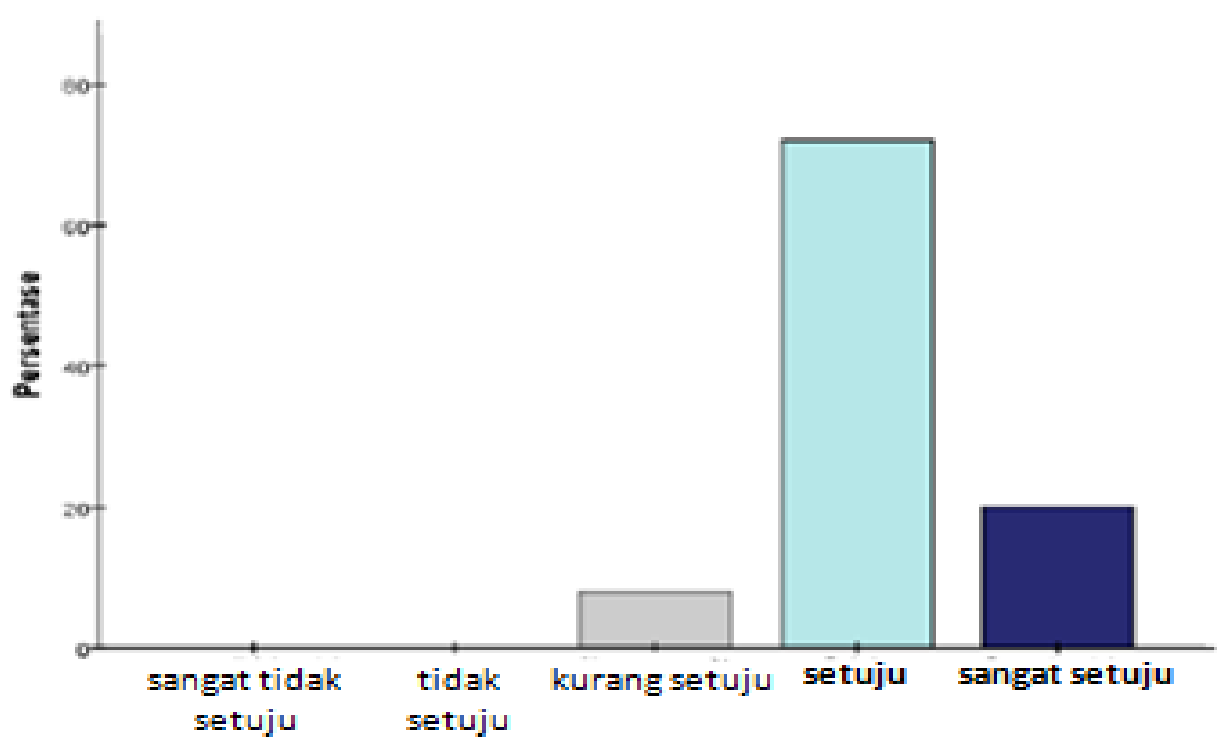

-PERSEPSI

Gambar 2. Distribusi frekuensi persepsi responden

(1) program kawasan konservasi, (2) pelaksanaan program suatu kawasan konservasi, (3) kendala yang dihadapi dan (4) manfaat kawasan konservasi. Persepsi yang baik terlihat ditunjukkan responden terhadap program (64,9\%), pelaksanaan $(55,8 \%)$, serta pemecahan kendalala $(55,7 \%)$ dan manfaat $(62 \%)$, seperti rincian tercantum pada Tabel 2 Tingkat dari persepsi responden dilihat berdasarkan rincian alat tangkap yang dipergunakan para nelayan menunjukkan bahwa arad, gillnet, tramell net, rawai, dogol dan bagan, umumnya berpersepsi yang baik (setuju) terhadap pengelolaan kawasan konservasi.

Tabel 3. Crosstabulasi alat tangkap dengan persepsi responden

\begin{tabular}{|c|c|c|c|c|c|}
\hline \multirow{2}{*}{ Alat Tangkap } & \multirow{2}{*}{ Rincian } & \multicolumn{3}{|c|}{ Persepsi } & \multirow{2}{*}{ TOTAL } \\
\hline & & Kurang setuju & Setuju & Sangat setuju & \\
\hline \multirow{2}{*}{ Arad } & Jumlah & 0 & 3 & 2 & 5 \\
\hline & Persen & $0.00 \%$ & $60,00 \%$ & $40,00 \%$ & $100.00 \%$ \\
\hline \multirow{2}{*}{ Gill net } & Jumlah & 1 & 19 & 5 & 25 \\
\hline & Persen & $4,00 \%$ & $76,00 \%$ & $20,00 \%$ & $100,00 \%$ \\
\hline \multirow{2}{*}{ Tramell } & Jumlah & 1 & 16 & 3 & 20 \\
\hline & Persen & $5,00 \%$ & $80,00 \%$ & $15,00 \%$ & $100,00 \%$ \\
\hline \multirow{2}{*}{ Rawai } & Jumlah & 2 & 17 & 6 & 25 \\
\hline & Persen & $8,00 \%$ & $68,00 \%$ & $24,00 \%$ & $100,00 \%$ \\
\hline \multirow{2}{*}{ Dogol } & Jumlah & 2 & 14 & 4 & 20 \\
\hline & Persen & $10,00 \%$ & $70,00 \%$ & $20,00 \%$ & $100,00 \%$ \\
\hline \multirow{2}{*}{ Bagan } & Jumlah & 2 & 3 & 0 & 5 \\
\hline & Persen & $40,00 \%$ & $60,00 \%$ & $0,00 \%$ & $100,00 \%$ \\
\hline \multirow{2}{*}{ TOTAL } & Jumlah & 8 & 72 & 20 & 100 \\
\hline & Persen & $8,00 \%$ & $72,00 \%$ & $20,00 \%$ & $100,00 \%$ \\
\hline
\end{tabular}


Tabel 4. Peran pemerintah memberikan peluang dalam berpartisipasi

\begin{tabular}{|c|c|c|c|c|c|c|c|}
\hline \multirow{2}{*}{ Peran Pemerintah } & \multirow{2}{*}{ No Pertanyaan } & \multicolumn{5}{|c|}{ Jawaban Responden } & \multirow{2}{*}{ Jumlah } \\
\hline & & TP & $\mathbf{J}$ & KK & $\mathbf{S}$ & SL & \\
\hline \multirow{3}{*}{ Perencanaan } & 1 & 26 & 17 & 43 & 12 & 2 & 100 \\
\hline & & & & & & & \\
\hline & 2 & 19 & 20 & 40 & 18 & 3 & 100 \\
\hline \multicolumn{2}{|c|}{ Jumlah } & 45 & 37 & 83 & 30 & 5 & 200 \\
\hline \multicolumn{2}{|c|}{ Persentase $(\%)$} & 22,5 & 18,5 & 41,5 & 15 & 2,5 & 100 \\
\hline \multirow{3}{*}{ Pelaksanaan } & 3 & 16 & 18 & 48 & 16 & 2 & 100 \\
\hline & 4 & 15 & 12 & 55 & 16 & 2 & 100 \\
\hline & 5 & 17 & 22 & 44 & 12 & 5 & 100 \\
\hline \multicolumn{2}{|c|}{ Jumlah } & 48 & 52 & 147 & 44 & 9 & 300 \\
\hline \multicolumn{2}{|c|}{ Persentase (\%) } & 16 & 17,3 & 49 & 14,7 & 3 & 100 \\
\hline
\end{tabular}

Ket: TP: Tidak pernah, J: Jarang, KK: Kadang-kadang, S: Sering, SL: Selalu

Dengan persentase terbesar $(80 \%)$ adalah responden tramell net dan berikutnya responden gillnet $76 \%$ berpersepsi baik terhadap pengelolaan suatu kawasan konservasi (Tabel 3).

Hasil pengukuran persepsi yang diperoleh dari responden menunjukan nelayan arad dan giilnet $80 \%$ setuju terhadap program pelaksanaan, nelayan tramell net $65 \%$ setuju terhadap pelaksanaan, nelayan dogol $70 \%$ setuju terhadap pemecahan kendala dan $70 \%$ responden tramell net setuju terhadap manfaat pengelolaan KKLD Kabupaten Ciamis. Rincian data dapat disimak dan terlihat pada Lampiran 1). Menurut Mulyadi dkk (2009) kepedulian masyarakat pada lingkungan, akan berdampak pada program yang berkelanjutan berbasis sumber daya alam.

\section{Peran pemerintah}

Berdasarkan kajian dari responden terhadap peran pemerintah, $42 \%$ responden memberikan jawaban kadangkadang pemerintah memberikan peluang untuk berpartisipasi dalam pengelolaan KKLD (Gambar 3). Pemerintah dalam tahap penyusunan suatu program kawasan konservasi kadang-kadang melibatkan 41,5\% responden. Sedangkan dalam pelaksanaan pengelolaan KKLD 49\% responden atau nelayan yang kadang-kadang dilibatkan oleh pemerintah (Tabel 4). 


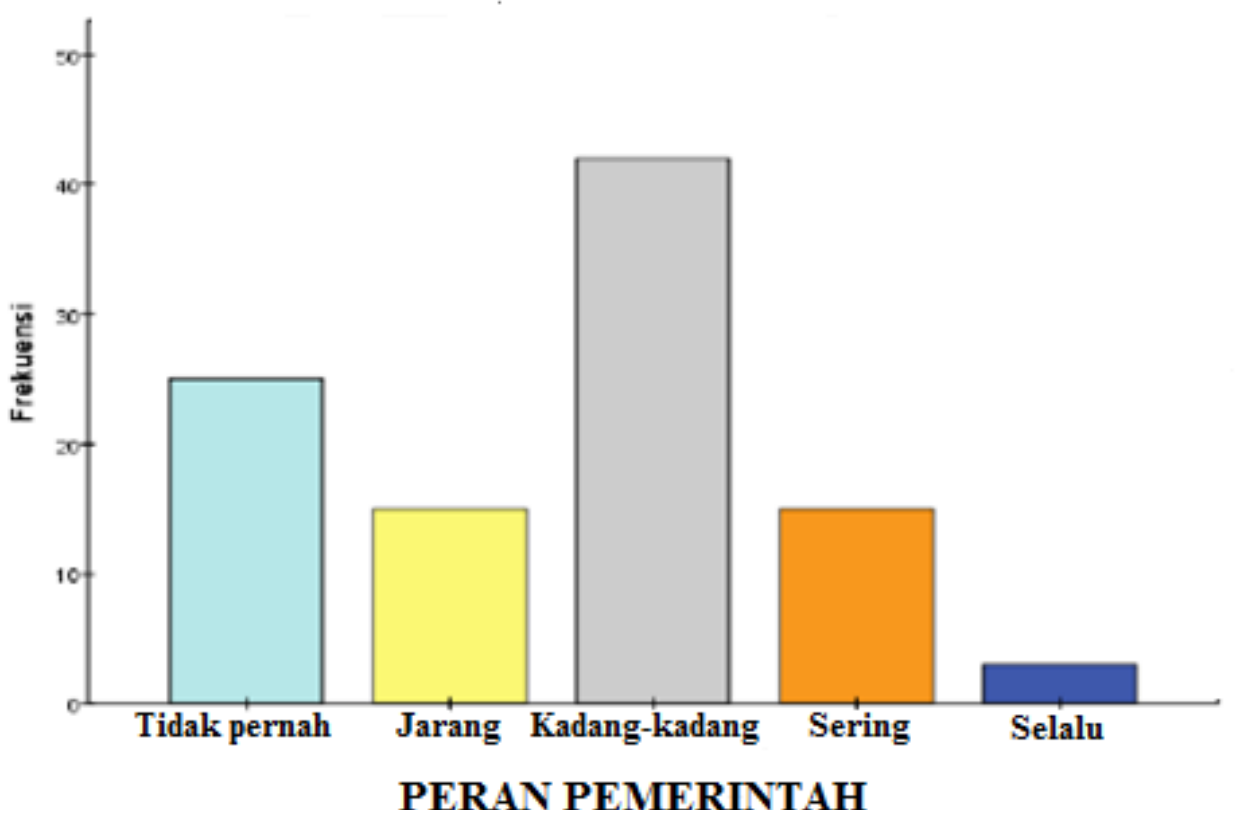

Gambar 3. Distribusi frekuensi peran pemerintah

Hasil crosstabulasi alat tengkap dengan peran pemerintah terlihat bahwa $60 \%$ responden arad dan dogol kadang- kadang dilibatkan atau diikutsertkan pemerintah dalam pengelolaan KKLD (Tabel 5).

Tabel 5. Crosstabulasi alat tangkap dengan peran pemerintah

\begin{tabular}{cccccccc}
\hline \multirow{2}{*}{$\begin{array}{c}\text { Alat } \\
\text { Tangkap }\end{array}$} & Rinci & \multicolumn{5}{c}{ Persepsi } & \multirow{2}{*}{ Total } \\
\cline { 3 - 7 } & T'Pernah & Jarang & Kadang & Sering & Selalu & \\
\hline \multirow{2}{*}{ Arad } & Jumlah & 1 & 1 & 3 & 0 & 0 & 5 \\
& Persen & $20 \%$ & $20 \%$ & $60 \%$ & $0 \%$ & $0 \%$ & $100 \%$ \\
\multirow{2}{*}{ Gill net } & Jumlah & 5 & 4 & 8 & 5 & 3 & 25 \\
& Persen & $20 \%$ & $16 \%$ & $32 \%$ & $20 \%$ & $12 \%$ & $100 \%$ \\
\multirow{2}{*}{ Tramell } & Jumlah & 4 & 3 & 10 & 3 & 0 & 20 \\
& Persen & $20 \%$ & $15 \%$ & $50 \%$ & $15 \%$ & $0 \%$ & $100 \%$ \\
\multirow{2}{*}{ Rawai } & Jumlah & 7 & 5 & 9 & 4 & 0 & 25 \\
& Persen & $28 \%$ & $20 \%$ & $36 \%$ & $16 \%$ & $0 \%$ & $100 \%$ \\
\multirow{2}{*}{ Dogol } & Jumlah & 5 & 1 & 12 & 2 & 0 & 20 \\
& Persen & $25 \%$ & $5 \%$ & $60 \%$ & $10 \%$ & $0 \%$ & $100 \%$ \\
\multirow{2}{*}{ Bagan } & Jumlah & 3 & 1 & 0 & 1 & 0 & 5 \\
& Persen & $60 \%$ & $20 \%$ & $0 \%$ & $20 \%$ & $0 \%$ & $100 \%$ \\
\multirow{2}{*}{ TOTAL } & Jumlah & 25 & 15 & 42 & 15 & 3 & 100 \\
& Persen & $25 \%$ & $15 \%$ & $42 \%$ & $15 \%$ & $3 \%$ & $100 \%$ \\
\hline
\end{tabular}


Sedangkan pemerintah kadang-kadang melibatkan mengikutsertakan responden alat tangkap rawai $76 \%$ dalam perencanaan pengelolaan dan $96 \%$ dalam pelaksanaan pengelolaan KKLD di Kabupaten Ciamis (Lampiran 2).

\section{SIMPULAN}

1. Sebagian besar nelayan Ciamis memberikan kesan yang baik (setuju) pada semua indikator persepsi tentang aeral Kawasan Konservasi Laut.

2. Pemerintah kurang berperan dalam memberikan ruang dan peluang bagi masyarkat untuk berpartisipasi.

\section{DAFTAR PUSATAKA}

Arikunto S. 2002. Prosedur Suatu Penelitian: Pendekatan Praktek. Edisi Revisi. Kelima. Rineka Cipta. Jakarta.

BPS Ciamis. 2011. Kabupaten Ciamis dalam Angka (Ciamis in Figurs) 2011. Badan Pusat Statistik. Ciamis.

Diniah, MP Sobari dan D Seftian. 2012. Pelayanan Pelabuhan Perikanan Nusantara (PPN) terhadap Kebutuhan Operasi Penagkapan Ikan. Jurnal Kebijakan Sosial dan Ekonomi Kelautan dan Perikanan Vol. 2 (1): 41-49

Manulang S. 1999. Kesepakatan Konservasi Masyarakat dalam Pengelolaan Kawasan Konservasi.

Mulyadi E, Okik Hendriyono, Cahyonugroho dan Nur Fitriani. 2009. Konservasi Hutan Mangrove sebagai Ekowisata. Jurnal Ilmiah Teknik Lingkungan 1: 51-57
Pomeroy R. dan F Berkes. 1997. Two to Tango: the Role of Government in Fisheries Co-Management. Marine Policy. 465-480 hal.

Sudiono G. 2008. Analisis pengelolaan terumbu karang pada kawasan konservasi laut daerah (KKLD) Pulau Randayan dan sekitarnya Kabupaten Bengkayang Provinsi Kalimantan Barat. Tesis. Program Pascasarjana pada Universitas Diponegoro 153 hal.

Susiatik T. 1998. Persepsi dan partisipasi masyarakat terhadap kegiatan pembangunan masyarakat desa hutan terpadu (PMDHT) di Desa Mojorebo Kecamatan Wirosari Kabupaten Dati II Grobogan Jawa Tengah. Tesis. Bogor: IPB.

Umar H. 2004. Riset Sumberdaya Manusia. Gramedia Pustaka Utama. Jakarta. 242 hal.

White A, LZ Hale, Y Renard and L Cortesi. 1994. Collaborative and Community Management of Coral Reefs: Lessons from Experience. Kumarian Press, Connecticut, USA. 130 hal. 